\title{
Use of regional climate model simulations as input for hydrological models for the Hindukush-Karakorum-Himalaya region
}

\author{
M. Akhtar ${ }^{1}$, N. Ahmad ${ }^{1}$, and M. J. Booij ${ }^{2}$ \\ ${ }^{1}$ Institute of Geology, University of the Punjab, Lahore, Pakistan \\ ${ }^{2}$ Department of Water Engineering and Management, University of Twente, Enschede, The Netherlands
}

Received: 20 February 2008 - Published in Hydrol. Earth Syst. Sci. Discuss.: 26 March 2008

Revised: 9 April 2009 - Accepted: 25 June 2009 - Published: 9 July 2009

\begin{abstract}
The most important climatological inputs required for the calibration and validation of hydrological models are temperature and precipitation that can be derived from observational records or alternatively from regional climate models (RCMs). In this paper, meteorological station observations and results of the PRECIS (Providing REgional Climate for Impact Studies) RCM driven by the outputs of reanalysis ERA 40 data and HadAM3P general circulation model (GCM) results are used as input in the hydrological model. The objective is to investigate the effect of precipitation and temperature simulated with the PRECIS RCM nested in these two data sets on discharge simulated with the HBV model for three river basins in the Hindukush-Karakorum-Himalaya (HKH) region. Six HBV model experiments are designed: HBV-Met, HBV-ERA and HBV-Had, HBV-Met ${ }_{\text {CRU-corrected, HBV-ERA }}$ Benchmark and HBV-Had ${ }_{\text {Benchmark }}$ where HBV is driven by meteorological stations data, data from PRECIS nested in ERA-40 and HadAM3P, meteorological stations CRU corrected data, ERA-40 reanalysis and HadAM3P GCM data, respectively. Present day PRECIS simulations possess strong capacity to simulate spatial patterns of present day climate characteristics. However, also some quantitative biases exist in the HKH region, where PRECIS RCM simulations underestimate temperature and overestimate precipitation with respect to CRU observations. The calibration and validation results of the HBV model experiments show that the performance of HBV-Met is better than the HBV models driven by other data sources. However, using input data series from sources different from the data used in the model calibration shows that HBV-Had is more efficient than other models and HBVMet has the least absolute relative error with respect to all other models. The uncertainties are higher in least efficient
\end{abstract}

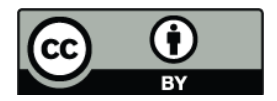

Correspondence to: M. Akhtar (akhtarme@yahoo.com) models (i.e. HBV-Met ${ }_{\mathrm{CRU}}$-corrected and HBV-ERA Benchmark $_{\text {) }}$ where the model parameters are also unrealistic. In terms of both robustness and uncertainty ranges the HBV models calibrated with PRECIS output performed better than other calibrated models except for HBV-Met which has shown a higher robustness. This suggests that in data sparse regions such as the HKH region data from regional climate models may be used as input in hydrological models for climate scenarios studies.

\section{Introduction}

Pakistan's economy is agro-based and highly dependent on the large scale Indus irrigation system. Most of the flow of the river Indus and its tributaries originates from the Hindukush-Karakorum-Himalaya (HKH) region (SIHP, 1990). Impacts of climate change and climate variability on the water resources are likely to affect irrigated agriculture and installed power capacity. Changes in flow magnitudes are likely to raise tensions among provinces, in particular with the downstream areas (Sindh province), with regard to reduced water flows in the dry season and higher flows and resulting flood problems during the wet season. Therefore, modeling the hydrological regime of the HKH region is critical for current and future water resources estimation, planning and operation in Pakistan.

To drive a hydrological model reliable information on local and regional climatological variables (e.g. temperature, precipitation, evapotranspiration) and their distribution in space and time is required. In many cases, the necessary information can be derived from observational data sets. For large scale hydrological applications and to investigate the impact of climate change on future water resources a hydrological model can be driven with the output from a general circulation model (GCM) (Watson et al., 1996). However, the spatial resolution of GCMs (generally about $250 \mathrm{~km}$ )

Published by Copernicus Publications on behalf of the European Geosciences Union. 
might be too coarse for hydrological modeling at the basin scale. One way to bridge this scale gap is through statistical downscaling (e.g. Wilby et al., 1999; Bergström et al., 2001; Pilling and Jones, 2002; Guo et al., 2002; Arnell, 2003; Booij, 2005) and an alternative approach is through dynamical downscaling (e.g. Hay et al., 2002; Hay and Clark, 2003; Fowler and Kilsby, 2007; Leander and Buishand, 2007; Bell et al., 2007; Graham et al., 2007). In dynamical downscaling, a regional climate model (RCM) uses GCM output as initial and lateral boundary conditions over a region of interest. The high horizontal resolution of a RCM (about 10$50 \mathrm{~km}$ ) is more appropriate for resolving the small-scale features of topography and land use, that have a major influence on climatological variables such as precipitation in the climate models. Moreover, the high resolution of the RCM is ideal to capture the spatial variability of precipitation as input to hydrological models (Gutowski et al., 2003). If the resolution of the RCM is not fine enough the bias of the modeled precipitation may lead to an unrealistic hydrological simulation.

Hydrological simulation in data sparse regions as the $\mathrm{HKH}$ region using RCM output as input involves a number of problems, including uncertainties in inputs, model parameters and model structure. The most important contribution to the input uncertainty comes from the GCM with additional uncertainties linked to the local scale patterns in downscaling of temperature, precipitation and evapotranspiration in a specific drainage basin (Bergström et al., 2001; Guo et al., 2002). Uncertainties in RCMs for specific parameters can be evaluated and quantified through ensemble simulation (Murphy et al., 2004; Giorgi and Francisco, 2000). Herein, a multitude of model runs is carried out under standardized conditions using either different models or using the same model but with different parameterization schemes, boundary conditions, initializations, resolutions etc.

In many hydrological studies statistical downscaling (Bergström et al., 2001; Pilling and Jones, 2002; Guo et al., 2002; Arnell, 2003; Booij, 2005) and dynamical downscaling (Fowler and Kilsby, 2007; Leander and Buishand, 2007; Bell et al., 2007; Graham et al., 2007) of different GCMs have been used to translate the assumed climate change into hydrological response. However, RCMs could also be used for generating time series of precipitation that are consistent across the region of the RCM. Kay et al. (2006) demonstrated the feasibility of dynamically downscaled data (without bias correction) for flood frequency estimation. The results showed that the RCM has a relatively good ability to reproduce flood frequency curves as compared to the flood frequency curves estimated using observed input data. In recent studies, outputs from RCMs have been used in hydrological models by firstly applying a bias correction to RCM simulated precipitation and temperature series (Fowler and Kilsby, 2007; Leander and Buishand, 2007; Bell et al., 2007; Graham et al., 2007).
The aim of this study is to examine the effect of precipitation and temperature simulated with the PRECIS RCM nested in different global data sets on discharge simulated with the HBV model for three river basins in the HKH region. The focus is on the comparison of spatial and temporal observed and simulated climate patterns and calibration and validation of $\mathrm{HBV}$ models including the assessment of the robustness of these models. Another study (Akhtar et al., 2008) has investigated expected changes in these climate patterns in the future and the impacts of these changes on the hydrological regime under different glacier coverage scenarios. The study area is described in Sect. 2. The HBV climatological inputs and the hydrological model are described in Sect. 3. The results of the PRECIS RCM simulations and calibration and validation results of HBV models are presented in Sect. 4. Finally, the conclusions and recommendations are given in Sect. 5.

\section{Description of study area}

Three river basins are selected for analysis: Hunza river basin, Gilgit river basin and Astore river basin. Daily observed discharge data for these three river basins are available at the outlets of the basins. These data cover the periods, 1975-1996 for the Hunza basin, 1962-1996 for the Gilgit basin and 1975-1996 for the Astore basin. The length of the records in the three river basins is not the same and there are some missing years in the discharge data. Therefore, in some cases the calibration and validation periods in the three river basins are not the same. Table 1 lists some features of the study basins and Fig. 1 shows the location of the three river basins. These three river basins are situated in the high mountainous HKH region with many peaks exceeding $7000 \mathrm{~m}$ and contain a large area of perennial snow and ice. The surface hydrology of these three river basins is dominated by snow and glacial melt. Climatic variables are strongly influenced by altitude. The HKH region receives a total annual rainfall amount of between 200 and $500 \mathrm{~mm}$, but these amounts are derived from valley-based stations and not representative for elevated zones. High-altitude precipitation estimates derived from accumulation pits runoff above $4000 \mathrm{~m}$ range from $1000 \mathrm{~mm}$ to more than $3000 \mathrm{~mm}$. These estimates depend on the site and time of investigation, as well as on the method applied (Winger et. al., 2005).

\section{Methodology}

\subsection{Climatological input}

\subsubsection{Observed data}

Daily observed meteorological data from the Gilgit and Astore meteorological stations are selected for the Gilgit and Astore river basins. There is no meteorological station in the 


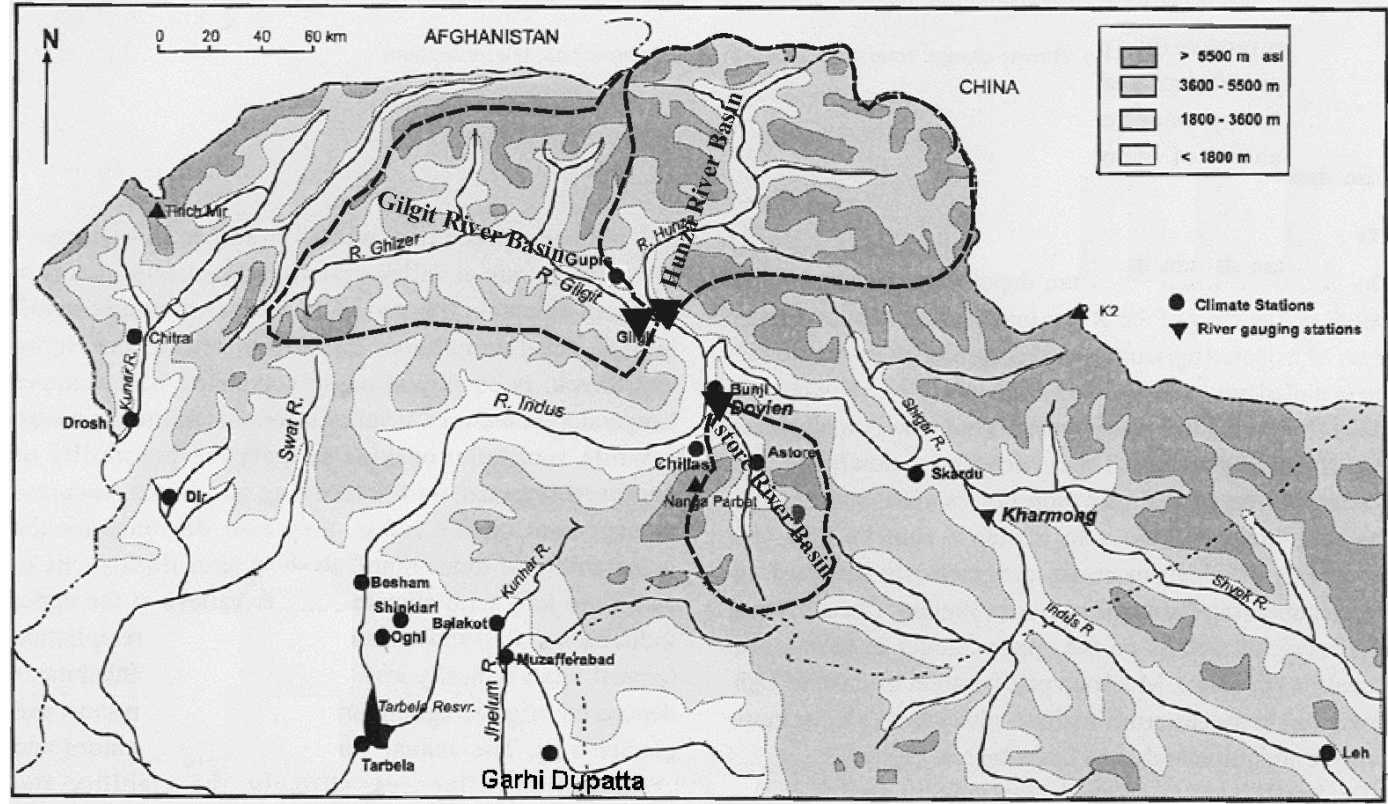

Fig. 1. Location of three river basins

Table 1. Characteristics of study area.

\begin{tabular}{lccc}
\hline & \multicolumn{3}{c}{ River basin } \\
\hline & Hunza & Gilgit & Astore \\
Discharge gauging station & Dainyor & Gilgit & Doyian \\
Latitude & $35^{\circ} 56^{\prime}$ & $35^{\circ} 56^{\prime}$ & $35^{\circ} 33^{\prime}$ \\
Longitude & $74^{\circ} 23^{\prime}$ & $74^{\circ} 18^{\prime}$ & $74^{\circ} 42^{\prime}$ \\
Elevation of gauging station $(\mathrm{m})$ & 1450 & 1430 & 1583 \\
Drainage area $\left(\mathrm{km}^{2}\right)$ & 13925 & 12800 & 3750 \\
Glacier covered area $\left(\mathrm{km}^{2}\right)$ & 4688 & 915 & 612 \\
Mean elevation $(\mathrm{m})$ & 4472 & 3740 & 3921 \\
$\%$ area above $5000 \mathrm{~m}$ & 35.8 & 2.9 & 2.8 \\
No. of meteorological stations & & & \\
Precipitation & - & 1 & 1 \\
Temperature & - & 1 & 1 \\
No. of PRECIS grid points & 6 & 5 & 2 \\
& & &
\end{tabular}

Hunza river basin, therefore neighboring Skardu meteorological station is used for calibration and validation of HBV. The meteorological station data are available for the period 19812002. The simulated PRECIS RCM precipitation and temperature data are compared with CRU observations (Mitchell and Jones, 2005) on a monthly basis. This data set is a $0.5^{\circ}$ latitude/longitude gridded dataset of monthly terrestrial surface climate for the period 1901-2002 derived from meteorological station observations. The uncertainties in CRU climatology averaged for multi-decadal periods are of the order of $0.5-1.3^{\circ} \mathrm{C}$ for temperature and $10-25 \%$ for precipitation, and are largest in regions having a sparse station network and high spatial variability, such as in many mountainous areas (New et al., 1999, 2000).

\subsubsection{Regional Climate Model outputs}

The RCM used in this study is PRECIS (Providing REgional Climate for Impact Studies) developed by the Hadley Centre of the UK Meteorological Office. The PRECIS RCM is based on the atmospheric component of the HadCM3 climate model (Gordon et al., 2000) and is extensively described in Jones et al. (2004). The atmospheric dynamics module of PRECIS is a hydrostatic version of the full primitive equations and uses a regular longitude-latitude grid in the horizontal and a hybrid vertical coordinate. For this study, the PRECIS model domain for South Asia has been set up with a horizontal resolution of $50 \times 50 \mathrm{~km}$. Some recent studies also have used RCM output at $50 \times 50 \mathrm{~km}$ resolution in hydrological studies (e.g. Graham et al., 2007; De Wit et al., 2007). Our domain roughly stretches over latitudes 12.5 to $40.5^{\circ} \mathrm{N}$ and longitudes 55.5 to $96.5^{\circ} \mathrm{E}$. This domain covers India, Pakistan, Afghanistan, the Tibetan Plateau and the HKH region (see Fig. 2). This domain allows full development of internal mesoscale circulation (e.g. monsoon circulation) and includes relevant regional forcings.

The representation of topography is an important feature of climate models as it has a strong impact on the simulated climate fields, in particular spatial precipitation distribution. Where terrain is flat for thousands of kilometers and away from coasts, the coarse resolution of a GCM may not matter. However, the HKH region has complex orographic features and several mountains exceed $7000 \mathrm{~m}$. Figure 2 shows the topography of the HadAM3P GCM, PRECIS RCM, GTOPO30 2MIN Digital Elevation Model (DEM) and the difference of representation of topography in the driving 

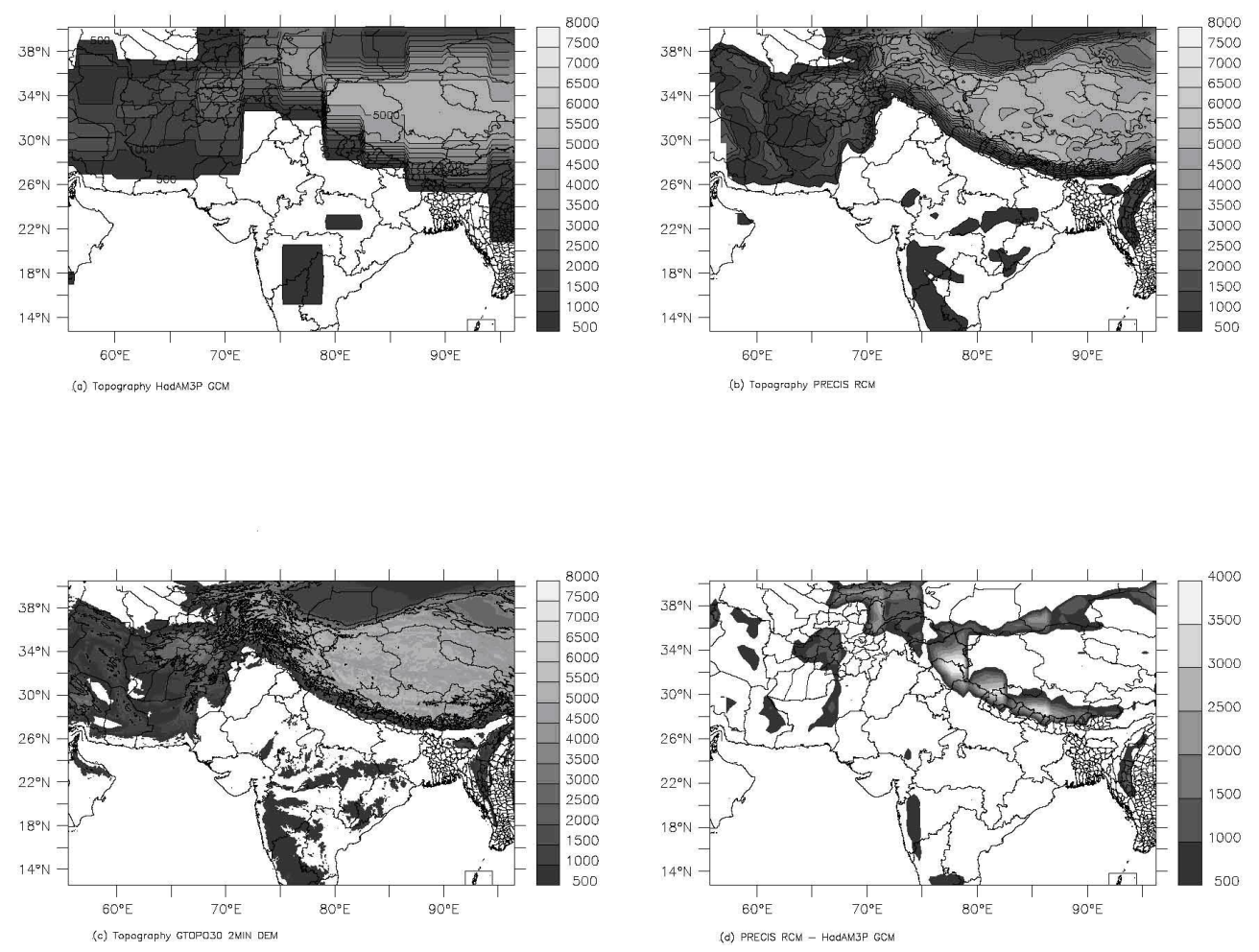

Fig. 2. Topography (m) of selected domain. (a) HadAM3P GCM. (b) PRECIS. (c) GTOPO30 2MIN DEM (d) Difference PRECIS RCM and GCM topography.

GCM and PRECIS RCM. The topography of PRECIS RCM (Fig. 2b) is very similar to the topography of GTOPO30 2MIN DEM (Fig. 2c). The difference in representation of topography in the driving GCM and PRECIS RCM (Fig. 2d) clearly shows that the higher resolution of PRECIS RCMs provides much better topographic details over the HKH region.

Two global data sets are used to drive the PRECIS model: data from the ERA-40 reanalysis project and the HadAM3P GCM. The horizontal resolution of HadAM3P boundary data is $150 \mathrm{~km}$ and for the present climate, it covers the period 1960-1990 (Wilson et al., 2005). ERA-40 is a re-analysis of meteorological observations produced by the European Centre for Medium-Range Weather Forecasts (ECMWF). It covers the period 1957-2002, has a horizontal resolution of 1.875 by 1.25 degrees $(\sim 187.5$ by $125 \mathrm{~km}$ ) and is extensively described in Uppala et al. (2005).

The PRECIS RCMs driven by HadAM3P and ERA-40 reanalysis boundary data are hereafter referred to as PRECIS Had and PRECIS ERA respectively. The time periods for PRECIS ERA and PRECIS Had are 1975-2001 and 19601990 respectively. The first year in each PRECIS experiment is considered as a spin-up period and these data are not used in any analysis. After post processing of each experiment the time series of temperature and precipitation for three river basins are generated.
To test the feasibility of runoff modeling in the HKH region there are two possibilities to use RCM data as input to hydrological models. One approach is to calibrate a hydrological model using bias corrected RCM data. Another approach is to calibrate a hydrological model using RCM data without applying any bias correction. However, in the second approach there is a risk that potential biases in RCM simulations may lead to unrealistic parameter values (see Akhtar et al., 2008). The PRECIS RCM simulated temperature and precipitation have biases as will be discussed in Sect. 4.2. These biases are corrected before applying the temperature and precipitation series as input to HBV. In data sparse regions like the $\mathrm{HKH}$ region $\mathrm{CRU}$ data can be used as reference data for bias correction. A simple bias correction approach as used by Durman et al. (2001) is applied. A correction factor is derived to correct for differences between the modeled monthly average and the CRU monthly average. Daily temperature and precipitation data series are bias corrected with these monthly correction factors. This approach provides a correction of monthly mean climate only and does not consider day to day variability. Recently, Fowler et al. (2007) also used this approach to study the impact of climate change on the water resources in north-west England. 


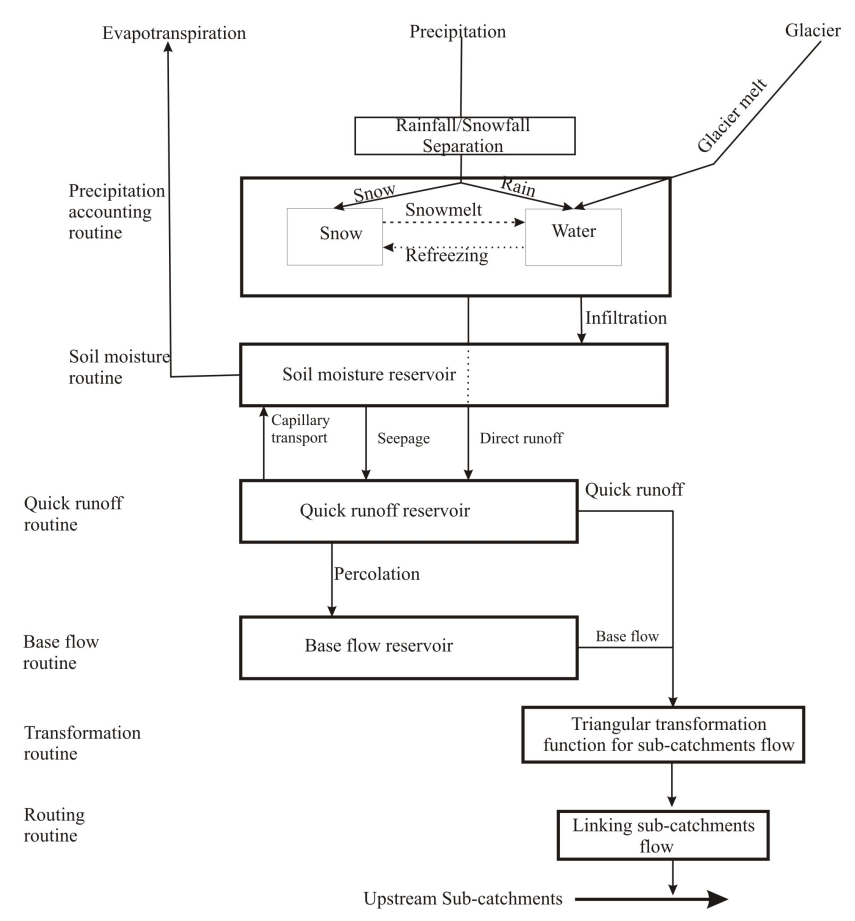

Fig. 3. Schematisation of the hydrological model HBV (based on Lindström et al., 1997).

\subsection{HBV hydrological model}

For the river discharge simulation, the hydrological model HBV of the Swedish Meteorological and Hydrological Institute (SMHI) is used (Bergström, 1995; Lindström et al., 1997). Using inputs from RCMs this model can reproduce the discharge fairly well, e.g. for the river Suir in Ireland (Wang et. al., 2006). It has been widely used in Europe and other parts of the world in e.g. climate change impact studies (Liden and Harlin, 2000; Bergström et al., 2001; Menzel and Bürger, 2002; Booij, 2005, Menzel et. al., 2006). In a recent study, Te Linde et al. (2008) compared the performances of two rainfall-runoff models (HBV and VIC) using different atmospheric forcing data sets and recommended the HBV model for climate change scenarios studies. HBV is a semi-distributed, conceptual hydrological model using sub-basins as the primary hydrological units. It takes into account area-elevation distribution and basic land use categories (glaciers, forest, open areas and lakes). Sub-basins are considered in geographically or climatologically heterogeneous basins. The model consists of six routines, which are a precipitation routine representing rainfall and snow, a soil moisture routine determining actual evapotranspiration and controlling runoff formation, a quick runoff routine and a base flow routine which together transform excess water from the soil moisture routine to local runoff, a transformation function and a routing routine (see Fig. 3).
Catchments in the HKH-region have extreme altitude differences and these affect the meteorological input variables strongly. The average basin altitude applied in HBV is $4472 \mathrm{~m}$ for the Hunza river basin, $3740 \mathrm{~m}$ for the Gilgit river basin and $3921 \mathrm{~m}$ for the Astore river basin whereas the average altitude applied for meteorological stations is $2210 \mathrm{~m}$ for the Hunza river basin, $1460 \mathrm{~m}$ for the Gilgit river basin and $2394 \mathrm{~m}$ for the Astore river basin. Default values of the elevation correction factor of precipitation and temperature are applied in HBV being pcalt $=0.1$ (i.e. $10 \% / 100 \mathrm{~m}$ ) for precipitation and tcalt $=0.6^{\circ} \mathrm{C} / 100 \mathrm{~m}$ for temperature. Precipitation values are multiplied with $1+h \times p$ calt, where $h$ is the altitude difference (hundreds of meters) between the average elevation of the catchment and the average elevation of precipitation stations (or grid cells). Temperature differences are added to or subtracted from the original temperature data.

In order to assess the performance of the model in simulating observed discharge behaviour an objective function $Y$ is used, which combines the Nash-Sutcliffe efficiency coefficient NS (Nash and Sutcliffe, 1970) and the relative volume error $R E$ and is defined as

$Y=\frac{N S}{1+|R E|}$

where

$$
\begin{gathered}
N S=1-\frac{\sum_{i=1}^{i=N}\left[Q_{s}(i)-Q_{o}(i)\right]^{2}}{\sum_{i=1}^{i=N}\left[Q_{o}(i)-\overline{Q_{o}}\right]^{2}} \\
R E=\frac{\sum_{i=1}^{i=N}\left[Q_{s}(i)-Q_{o}(i)\right]}{\sum_{i=1}^{i=N} Q_{o}(i)}
\end{gathered}
$$

where $i$ is the time step, $N$ is the total number of time steps, $Q_{s}$ represents simulated discharge, $Q_{o}$ is observed discharge and $\overline{Q_{o}}$ is the mean of $Q_{o}$ over the calibration or validation period. For a favorable model performance, the efficiency $N S$ should be close to 1 and the $R E$ value should be close to zero resulting in a $Y$ value close to 1 .

Depending on the source of input data, i.e. meteorological stations data, PRECIS ERA, PRECIS Had, meteorological stations CRU corrected data, ERA-40 reanalysis and HadAM3P GCM, six HBV models are developed hereafter referred to as HBV-Met, HBV-ERA, HBVHad, HBV-Met ${ }_{\text {CRU-corrected, HBV-ERA }}$ Benchmark $_{\text {and HBV- }}$ $\mathrm{Had}_{\text {Benchmark }}$ respectively. The first step in the calibration of the HBV models is the selection of calibration parameters. The parameters are selected on the basis of physical reasoning, previous studies and univariate sensitivity analyses. For each river basin, a univariate sensitivity analysis is performed to assess the influence of individual parameters on the performance of the model. This is done by varying 
Table 2. Biases in mean temperature $\left({ }^{\circ} \mathrm{C}\right)$ as simulated with PRECIS ERA, PRECIS Had, ERA-40 and HadAM3P relative to CRU reference data for different seasons and river basins (Summer = April-September, Winter = October-March).

\begin{tabular}{lcccccccccccc}
\hline Season & \multicolumn{3}{c}{ PRECIS ERA } & \multicolumn{3}{c}{ PRECIS Had } & \multicolumn{3}{c}{ ERA-40 } & \multicolumn{3}{c}{ HadAM3P } \\
\hline & Astore & Gilgit & Hunza & Astore & Gilgit & Hunza & Astore & Gilgit & Hunza & Astore & Gilgit & Hunza \\
\hline & & & & \multicolumn{1}{c}{ Temperature $\left({ }^{\circ} \mathrm{C}\right)$} \\
\hline Summer & -1.1 & -4.5 & -6.6 & -2.4 & -2.2 & -5.5 & -1.8 & -5.3 & -3.8 & -2.6 & -3.3 & -6.3 \\
Winter & -2.9 & -7.2 & -7.3 & -8.1 & -7.1 & -8.9 & -3.6 & -7.7 & -4.1 & -7.6 & -8.5 & -10.9 \\
Annual & -2.0 & -5.9 & -7.0 & -5.2 & -4.6 & -7.2 & -2.7 & -6.5 & -3.9 & -5.1 & -5.9 & -8.6 \\
\hline
\end{tabular}

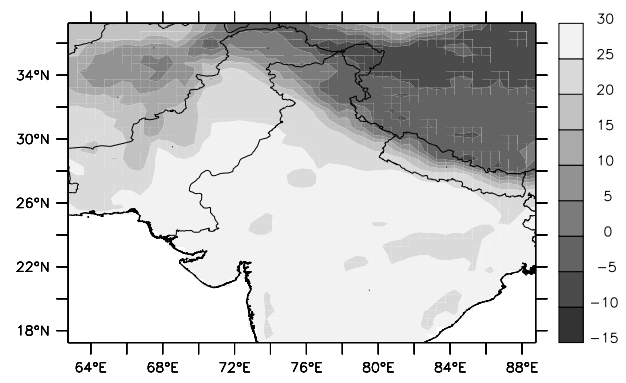

(a) CRU

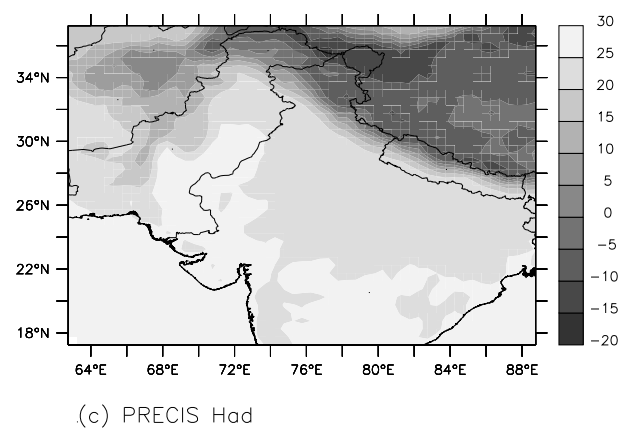

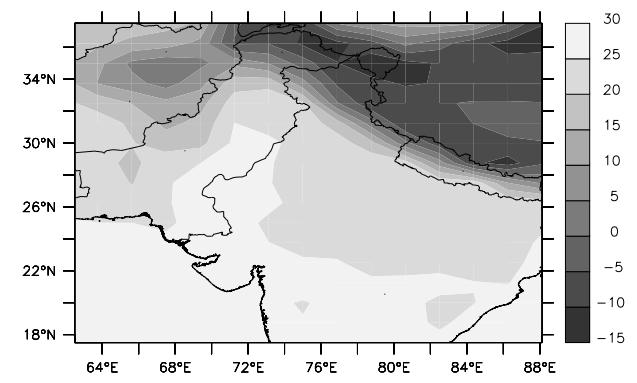

(b) HadAM3P

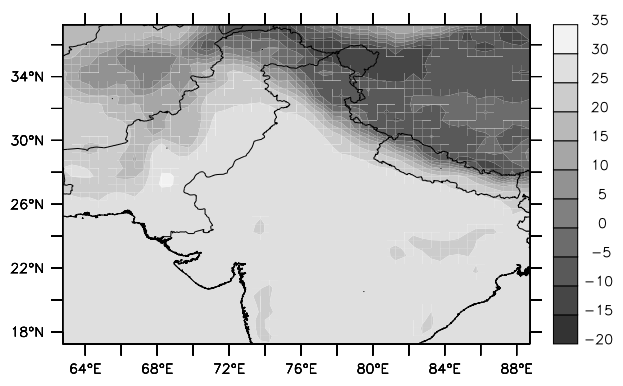

(d) PRECIS ERA

Fig. 4. Observed and simulated patterns of annual mean temperature $\left({ }^{\circ} \mathrm{C}\right)$ for $(\mathbf{a}) \mathrm{CRU}$ data, (b) GCM HadAM3P, (c) PRECIS Had and (d) PRECIS ERA.

the value of one parameter while keeping other parameters constant (default value). For the three river basins, the parameters gmelt (Glacier melting factor), FC (Maximum soil moisture storage), TT (threshold temperature for precipitation), DTTM (value added to TT to give the threshold temperature for snowmelt), PERC (Percolation from the upper to the lower response box), and cfmax (Snowmelt factor) are found to be most sensitive. There appears to be a strong interdependence among four of these parameters (gmelt, FC, $D T T M$ and $T T$ ). In the second step, a multivariate sensitivity analysis is performed to optimize these interdependent and sensitive parameters of HBV-Met, HBV-ERA, HBVHad, HBV-Met ${ }_{\mathrm{CRU}-\text { corrected, }}$ HBV-ERA Benchmark $_{\text {and }}$ HBV-
$\mathrm{Had}_{\text {Benchmark }}$ for each river basin. The values of the remaining key parameters (PERC and cfmax) are optimized by univariate sensitivity analysis. For the remaining parameters default values as described in SMHI (2005) are used.

\section{Results and discussion}

\subsection{Spatial patterns of observed and simulated climate for South Asia}

Figure 4 shows that HadAM3P, PRECIS Had and PRECIS ERA capture the basic spatial patterns of CRU climatology 

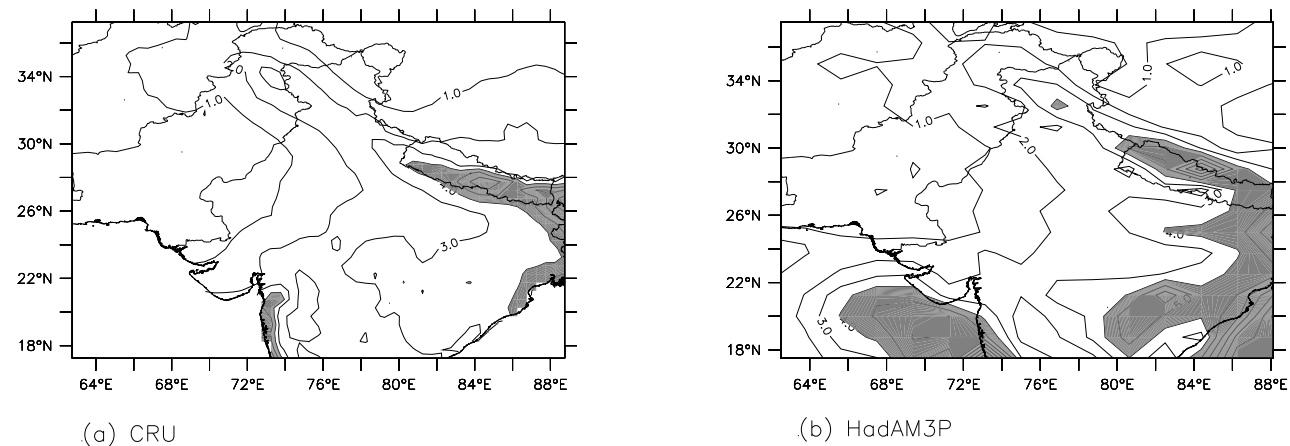

(b) $\operatorname{HadAM} 3 \mathrm{P}$
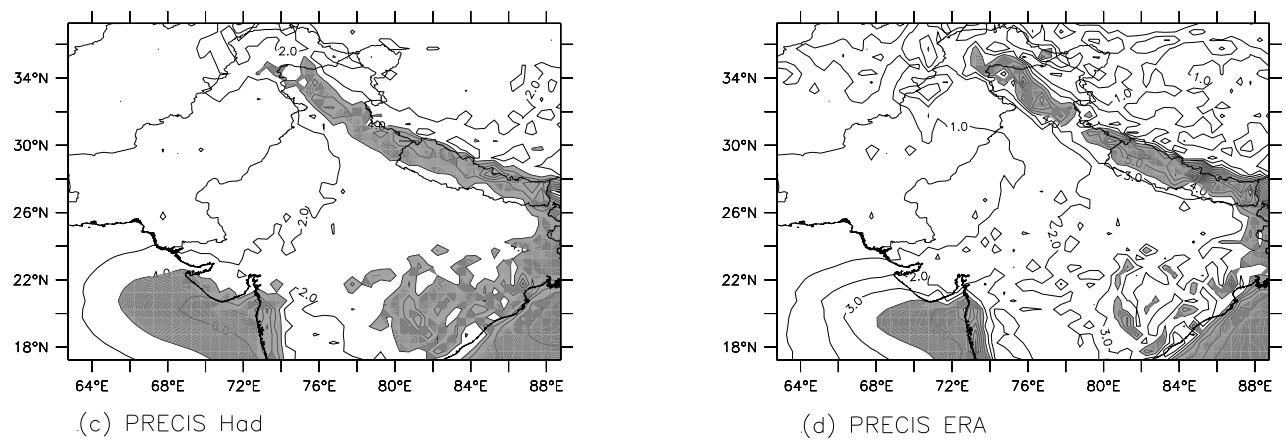

Fig. 5. Observed and simulated patterns of annual mean precipitation (mm/day) for (a) CRU data, (b) GCM HadAM3P, (c) PRECIS Had and (d) PRECIS ERA. The shaded area indicates precipitation above $4 \mathrm{~mm} /$ day in all panels.

reasonably well. Compared to the CRU observations the simulated PRECIS Had and PRECIS ERA temperature is relatively low in the Tibetan Plateau and in the HKH region. The sharply rising escarpment over the Tibetan Plateau and $\mathrm{HKH}$ region results in cooler mountain areas in the PRECIS simulations. In many of these areas, the differences in temperature are due to the higher resolution of topography in PRECIS $\mathrm{RCM}$ as compared to the driving GCM.

The spatial patterns of annual mean precipitation as simulated by HadAM3P, PRECIS Had, PRECIS ERA and CRU observations are shown in Fig. 5. The precipitation is maximum over Western Ghats, Eastern Ghats and over the HKH region. The PRECIS RCM simulated precipitation pattern is quite similar to the CRU observations, indicating that the PRECIS RCM simulations provide an adequate representation of present day conditions. However, some quantitative biases in the spatial patterns exist. In both PRECIS Had and PRECIS ERA wet biases are present over the HKH region. Since the biases are present in both PRECIS Had and PRECIS ERA, some of these biases may be due to errors in the internal model physics of PRECIS RCM and may be related to the inadequate representation of the land surface. The model currently uses vegetation distribution and soil properties based on the climatology of Wilson and Henderson-
Sellers (1985). However, this data set does not vary temporally, and seasonal variations in surface albedo, roughness and leaf area index could have a significant effect on the climate (Hudson and Jones, 2002).

\subsection{Temporal patterns of observed and simulated cli- mate over selected river basins}

\subsubsection{Temperature}

For three river basins, the mean annual cycles of temperature from CRU data, meteorological stations observations and PRECIS RCM simulations are shown in Fig. 6. The CRU data and meteorological stations observations show that a mean annual cycle is present in all river basins. The highest mean temperature is reached in July while the lowest mean temperature is observed in January. The meteorological stations recorded temperature is higher compared to CRU temperature and PRECIS simulated temperature. This difference is mainly because of the fact that meteorological stations are located in valleys and do not represent the temperature in high mountains. The influence of height is observed in CRU observations i.e. the highest mean temperature is observed in the lowest river basin (Astore) while the lowest mean temperature is observed in the highest river basin 
Table 3. Biases in precipitation (\%) as simulated with PRECIS ERA, PRECIS Had, ERA-40 and HadAM3P relative to CRU reference data for different seasons and river basins (Summer = April-September, Winter = October-March).

\begin{tabular}{|c|c|c|c|c|c|c|c|c|c|c|c|c|}
\hline \multirow[t]{2}{*}{ Season } & \multicolumn{3}{|c|}{ PRECIS ERA } & \multicolumn{3}{|c|}{ PRECIS Had } & \multicolumn{3}{|c|}{ ERA-40 } & \multicolumn{3}{|c|}{ HadAM3P } \\
\hline & Astore & Gilgit & Hunza & Astore & Gilgit & Hunza & Astore & Gilgit & Hunza & Astore & Gilgit & Hunza \\
\hline & \multicolumn{12}{|c|}{ Precipitation (\%) } \\
\hline Summer & 91 & 31 & 310 & 37 & 3 & 248 & 273 & 115 & 794 & 52 & 13 & 243 \\
\hline Winter & 345 & 118 & 305 & 82 & -12 & 112 & 238 & 75 & 13 & 155 & 87 & 105 \\
\hline Annual & 218 & 74 & 308 & 59 & -4 & 180 & 255 & 95 & 403 & 103 & 50 & 174 \\
\hline
\end{tabular}

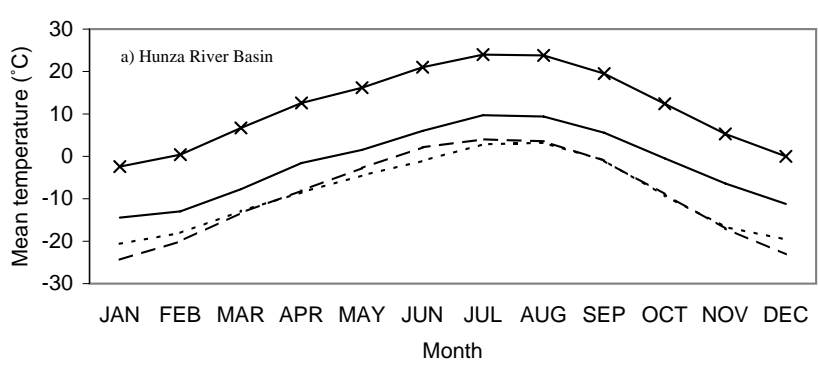

CRU - - - - - - PRECIS ERA - - - PRECIS Had $\longrightarrow$ Met. Observations

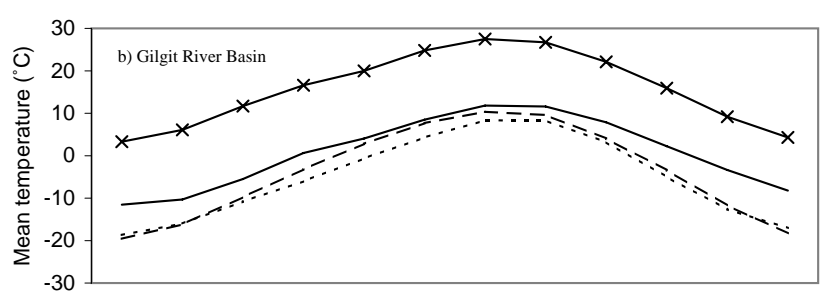

JAN FEB MAR APR MAY JUN JUL AUG SEP OCT NOV DEC Month
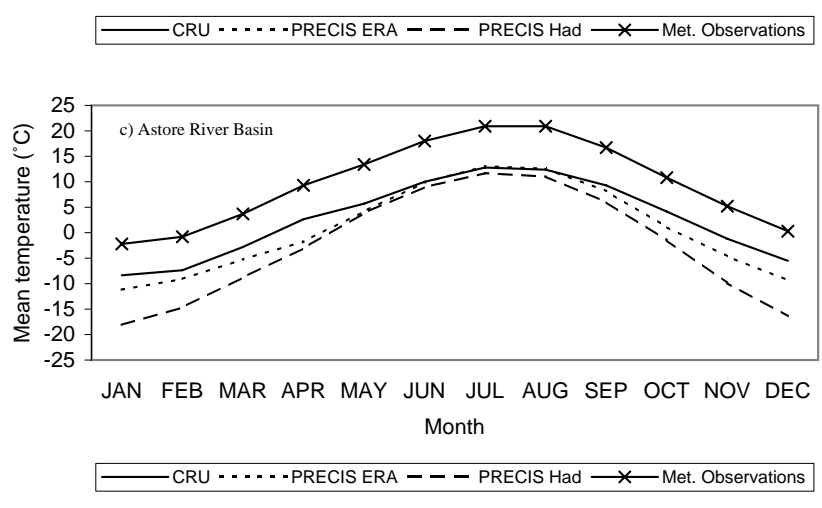

Fig. 6. Mean annual cycle of temperature over (a) Hunza river basin (b) Gilgit river basin (c) Astore river basin as simulated with PRECIS RCMs, CRU data and meteorological stations observations $\left[{ }^{\circ} \mathrm{C}\right]$.

(Hunza). The influence of height is also present in meteorological stations observations e.g. the highest mean temperature is observed at the lowest station (Gilgit at $1460 \mathrm{~m}$ ) while the lowest mean temperature is observed at the highest station (Astore at $2394 \mathrm{~m}$ ). Generally, in all river basins the characteristics of the mean annual cycle of temperature in PRECIS RCM simulations are similar to CRU observations, i.e. the highest mean temperature is observed in July and the lowest in January. This is a sign indicating the correctness of the representation of basic physical processes in the model. In some months, PRECIS Had and PRECIS ERA simulations have some close agreement with each other. The biases in temperature in driving data and PRECIS RCM simulations with respect to CRU observations are presented in Table 2. In all three river basins, both driving forcing data and PRECIS RCM simulations underestimate mean temperature. Generally, PRECIS RCM simulated bias is somewhat less compared to the respective biases in driving forcing data. The cold bias in PRECIS RCM simulations may be because of the deficiencies of the GCM simulations (McGregor, 1997). Moreover, the cold bias observed over mountain regions is a common feature of regional climate simulations over different regions of the world (Giorgi et al., 2004; Solman et al., 2008). Therefore, the PRECIS RCM itself may introduce some of the cold bias as well. It is also observed that cold biases in the winter half-year (i.e. October to March) are relatively higher than in the summer half-year (i.e. April to September). This may be because of the fact that PRECIS RCM simulations give excessive precipitation during the winter half-year (Fig. 7), which tends to result in excessively wet soils, which cause high latent heat flux, low sensible heat flux, and as a result surface cooling (Bonan, 1998). The magnitude of the cold bias depends on the driving boundary data, e.g. the cold bias during winter is higher in PRECIS Had simulations while it is somewhat less during summer when compared with PRECIS ERA simulations. This latter phenomenon might occur because of less precipitation during these months in PRECIS Had compared to PRECIS ERA.

\subsubsection{Precipitation}

For three river basins, the mean annual cycles of precipitation from CRU data, meteorological stations observations and PRECIS RCM simulations are shown in Fig. 7. Generally, 

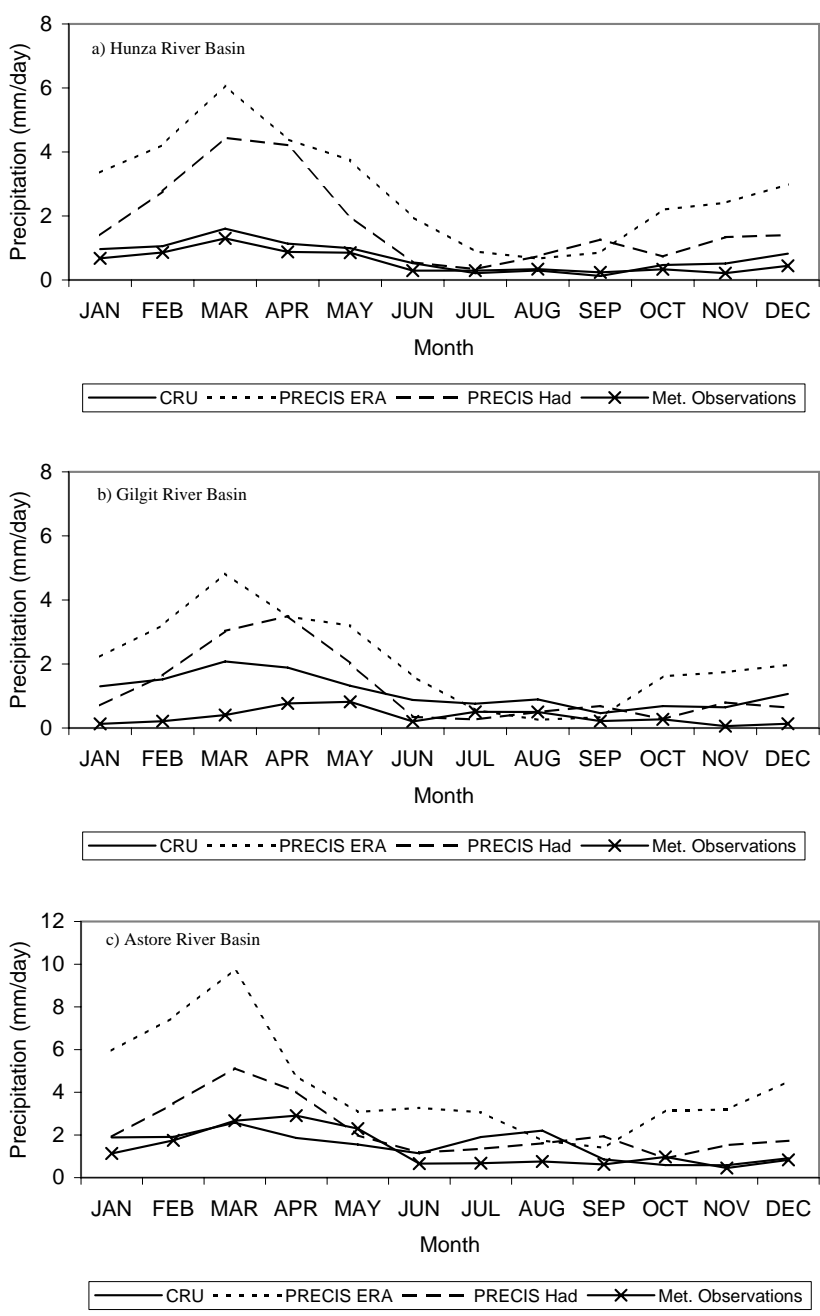

Fig. 7. Mean annual cycle of precipitation over (a) Hunza river basin (b) Gilgit river basin (c) Astore river basin as simulated with PRECIS RCMs, CRU data and meteorological stations observations [mm/day].

valley-based meteorological stations underestimate precipitation compared to CRU data mainly because of the fact that meteorological stations are not representative for elevated zones (Winger et al., 2005). The mean annual cycle of precipitation exhibits a stronger variability than the annual cycle of temperature. Overall, for a particular PRECIS RCM experiment all three-study basins have the same patterns. Generally, all PRECIS RCM simulations overestimate precipitation in all three river basins. They give higher precipitation during the winter half-year (October to March) compared to the summer half-year (April to September). Table 3 presents the biases in precipitation of driving forcing data and PRECIS RCM simulations with respect to CRU data. Generally, the PRECIS RCM simulated precipitation bias is somewhat less compared to the respective biases in driving forcing simulated precipitation. The magnitude of biases in PRECIS
Had are somewhat less compared to PRECIS ERA, although one may expect the opposite. A detailed regional analysis of the South Asian domain shows that this fact is observed only in the HKH region (Akhtar, 2008) which is may be due to deficiencies in global forcing data. Another reason for large biases may be due to the fact that the HKH region receives (relatively) small amounts of precipitation and a small absolute increase/decrease in precipitation data derived from PRECIS simulations gives a larger percentual precipitation bias. The wet bias can have different causes. Giorgi and Marinucci (1996) showed that the simulation of precipitation may be sensitive to model resolution regardless of the topographic forcing. In particular, in their experiments precipitation tends to increase at finer resolutions. Greater topographic forcing at higher resolution would then further strengthen this effect. Since the study area has a steep topography, this may lead to excessive accumulated orographic precipitation in RCMs (Giorgi et al., 1994).

\subsection{Calibration and validation of $\mathrm{HBV}$ model}

The results of the multiple sensitivity analyses with six calibrated HBV models for different data sources are described in this section. Table 4 shows the calibrated HBV parameter values for three river basins with different input data sets. It shows that the parameter values of HBV-Met, HBV-

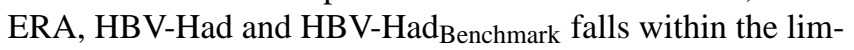
its described in other studies whereas the parameter values of HBV-Met $_{\mathrm{CRU}}$-corrected and HBV-ERA ${ }_{\text {Benchmark }}$ exceeds the limits described in other studies (e.g. Uhlenbrook et al.,1999; Krysanova et al., 1999; SMHI, 2005; Booij, 2005). The parameter values vary between the different data sources in three river basins. During calibration the threshold temperature TT turned out to be the most critical parameter, because generally all PRECIS RCM simulations (Figs. 6 and 7) show that most of the precipitation in the HKH region occurs under freezing conditions.

Table 5 presents the efficiency $Y$, Nash-Sutcliffe coefficient $N S$ and relative volume error $R E$ for the six HBV models during calibration and validation periods for the three river basins. All six HBV models show that during the calibration period the relative volume error is very small which indicates that the average simulated and observed discharge are close to each other. General testing of conceptual models (Rango, 1992) has shown that $N S$ values higher than 0.8 are above average for runoff modeling in glaciated catchments. Therefore, $N S$ values during calibration are satisfactory for all HBV models and the highest values are achieved by HBVERA $_{\text {Benchmark }}$ (e.g. $0.67<N S<0.92$ ). Figure 8 presents the observed and simulated discharge of six HBV models during the hydrological year 1986 for the Hunza river basin. The figures for the other two river basins during the calibration period and figures for all river basins during the validation period are not given for redundancy. During the calibration period the peak values are generally underestimated and 
Table 4. Parameter values for HBV for three river basins with six different input data sets.

\begin{tabular}{|c|c|c|c|c|c|c|c|}
\hline \multirow[t]{2}{*}{ Model } & \multirow[t]{2}{*}{ River basin } & \multicolumn{6}{|c|}{ Parameter } \\
\hline & & $\operatorname{cfmax}\left(\mathrm{mm} /{ }^{\circ} \mathrm{C} / \mathrm{d}\right)$ & DTTM $\left({ }^{\circ} \mathrm{C}\right)$ & $\mathrm{FC}(\mathrm{mm})$ & gmelt $\left(\mathrm{mm} /{ }^{\circ} \mathrm{C} / \mathrm{d}\right)$ & PERC (mm/d) & $\mathrm{TT}\left({ }^{\circ} \mathrm{C}\right)$ \\
\hline \multirow[t]{3}{*}{ HBV-Met } & Hunza & 3 & 0 & 1500 & 3.5 & 0.5 & 0 \\
\hline & Gilgit & 3 & -2.5 & 700 & 4 & 0.8 & -2 \\
\hline & Astore & 4.5 & -2.5 & 700 & 4.5 & 0.8 & -2.5 \\
\hline \multirow[t]{3}{*}{ HBV-ERA } & Hunza & 3.2 & -1 & 100 & 3.5 & 0.5 & -0.3 \\
\hline & Gilgit & 3 & -1.5 & 700 & 3.5 & 0.5 & -1.5 \\
\hline & Astore & 3.5 & -1.5 & 700 & 4 & 0.5 & 0 \\
\hline \multirow[t]{3}{*}{ HBV-Had } & Hunza & 3 & -1.5 & 1100 & 4 & 0.5 & 0.4 \\
\hline & Gilgit & 3 & -2.5 & 700 & 3.4 & 0.9 & -2 \\
\hline & Astore & 3.5 & -2.5 & 700 & 4.5 & 0.5 & -1.5 \\
\hline \multirow[t]{3}{*}{${ }_{\text {HBV-Met }}$ CRU-correected } & Hunza & 2.9 & -6.5 & 1400 & 5 & 0.5 & -1.5 \\
\hline & Gilgit & 3 & -6 & 500 & 5 & 0.5 & -6 \\
\hline & Astore & 5.5 & -6 & 100 & 5.5 & 0.5 & -6 \\
\hline \multirow{3}{*}{ HBV-ERA $A_{\text {Benchmark }}$} & Hunza & 3 & -8 & 1500 & 4 & 0.5 & -6 \\
\hline & Gilgit & 3.1 & -8 & 100 & 4 & 0.5 & -48 \\
\hline & Astore & 4 & -6.25 & 200 & 4 & 0.5 & -6 \\
\hline \multirow{3}{*}{ HBV-Had Benchmark } & Hunza & 3 & -2 & 1600 & 4 & 0.5 & 0 \\
\hline & Gilgit & 3 & -2 & 700 & 5 & 0.5 & 0.5 \\
\hline & Astore & 3 & -2.5 & 500 & 4 & 0.5 & -1.5 \\
\hline
\end{tabular}

Table 5. Performance of six HBV models during calibration and validation in different river basins.

\begin{tabular}{|c|c|c|c|c|c|c|c|c|c|}
\hline \multirow[t]{2}{*}{ Model } & \multirow[t]{2}{*}{ River basin } & \multicolumn{4}{|c|}{ Calibration } & \multicolumn{4}{|c|}{ Validation } \\
\hline & & Period & NS & $\mathrm{RE} \%$ & $\mathrm{Y}$ & Period & NS & $\mathrm{RE} \%$ & $\mathrm{Y}$ \\
\hline \multirow[t]{3}{*}{ HBV-Met } & Hunza & 1981-1990 & 0.87 & -0.4 & 0.87 & 1991-1996 & 0.91 & -1.4 & 0.90 \\
\hline & Gilgit & 1981-1990 & 0.83 & -0.4 & 0.82 & 1991-1996 & 0.77 & -11.7 & 0.69 \\
\hline & Astore & 1981-1990 & 0.68 & -1.2 & 0.67 & 1991-1996 & 0.73 & -15.2 & 0.63 \\
\hline \multirow[t]{3}{*}{ HBV-ERA } & Hunza & 1981-1990 & 0.89 & 0 & 0.89 & 1991-1996 & 0.83 & 1.6 & 0.81 \\
\hline & Gilgit & 1981-1990 & 0.75 & 0.2 & 0.75 & 1991-1996 & 0.76 & -10.6 & 0.69 \\
\hline & Astore & 1981-1990 & 0.58 & 0 & 0.58 & 1991-1996 & 0.52 & -22.7 & 0.42 \\
\hline \multirow[t]{3}{*}{ HBV-Had } & Hunza & 1981-1990 & 0.77 & 0 & 0.77 & 1975-1980 & 0.70 & -25.4 & 0.56 \\
\hline & Gilgit & 1981-1990 & 0.74 & 0.3 & 0.74 & $1965-1970$ & 0.76 & -8.8 & 0.70 \\
\hline & Astore & 1981-1990 & 0.62 & -2.3 & 0.61 & $1975-1980$ & 0.62 & 5.0 & 0.59 \\
\hline \multirow{3}{*}{${ }_{\mathrm{HBV}}-\mathrm{Met}_{\mathrm{CRU}}$-corrected } & Hunza & 1981-1990 & 0.84 & 0 & 0.84 & 1991-1996 & 0.91 & -2.7 & 0.88 \\
\hline & Gilgit & 1981-1990 & 0.73 & -1.4 & 0.71 & 1991-1996 & 0.71 & -8.4 & 0.65 \\
\hline & Astore & 1981-1990 & 0.61 & -2.7 & 0.60 & 1991-1996 & 0.70 & -14.4 & 0.61 \\
\hline \multirow{3}{*}{ HBV-ERA Benchmark } & Hunza & 1981-1990 & 0.92 & 0.4 & 0.92 & 1991-1996 & 0.91 & 10.5 & 0.82 \\
\hline & Gilgit & 1981-1990 & 0.82 & -0.2 & 0.82 & 1991-1996 & 0.75 & -7.1 & 0.70 \\
\hline & Astore & 1981-1990 & 0.67 & -0.6 & 0.66 & 1991-1996 & 0.68 & -13.6 & 0.60 \\
\hline \multirow[t]{3}{*}{ HBV-Had ${ }_{\text {Benchmark }}$} & Hunza & 1981-1990 & 0.74 & -0.1 & 0.74 & $1975-1980$ & 0.67 & -22.3 & 0.55 \\
\hline & Gilgit & 1981-1990 & 0.64 & -5.8 & 0.61 & $1965-1970$ & 0.70 & -9.8 & 0.64 \\
\hline & Astore & 1981-1990 & 0.60 & -1.4 & 0.59 & 1975-1980 & 0.62 & 12.7 & 0.55 \\
\hline
\end{tabular}

discharge during low flow periods is well simulated by the HBV models. During the calibration period efficiency $(Y)$ values and visual inspection of hydrographs show that performance of all HBV models is satisfactory.

During validation the $R E$ values show that in most cases all models underestimate discharge in the three river basins. Overall, only two out of eighteen combinations of river basins and HBV models shows a higher efficiency $(Y)$ in the validation compared to the calibration mainly due to the large volume errors. The values of the performance criteria show that during the validation period overall performance of HBV-Met (e.g. $0.63<Y<0.90$ ) is somewhat better compared to the overall performance of HBV models driven by PRECIS outputs and driving forcing data (e.g. $0.42<Y<0.82$ ). 

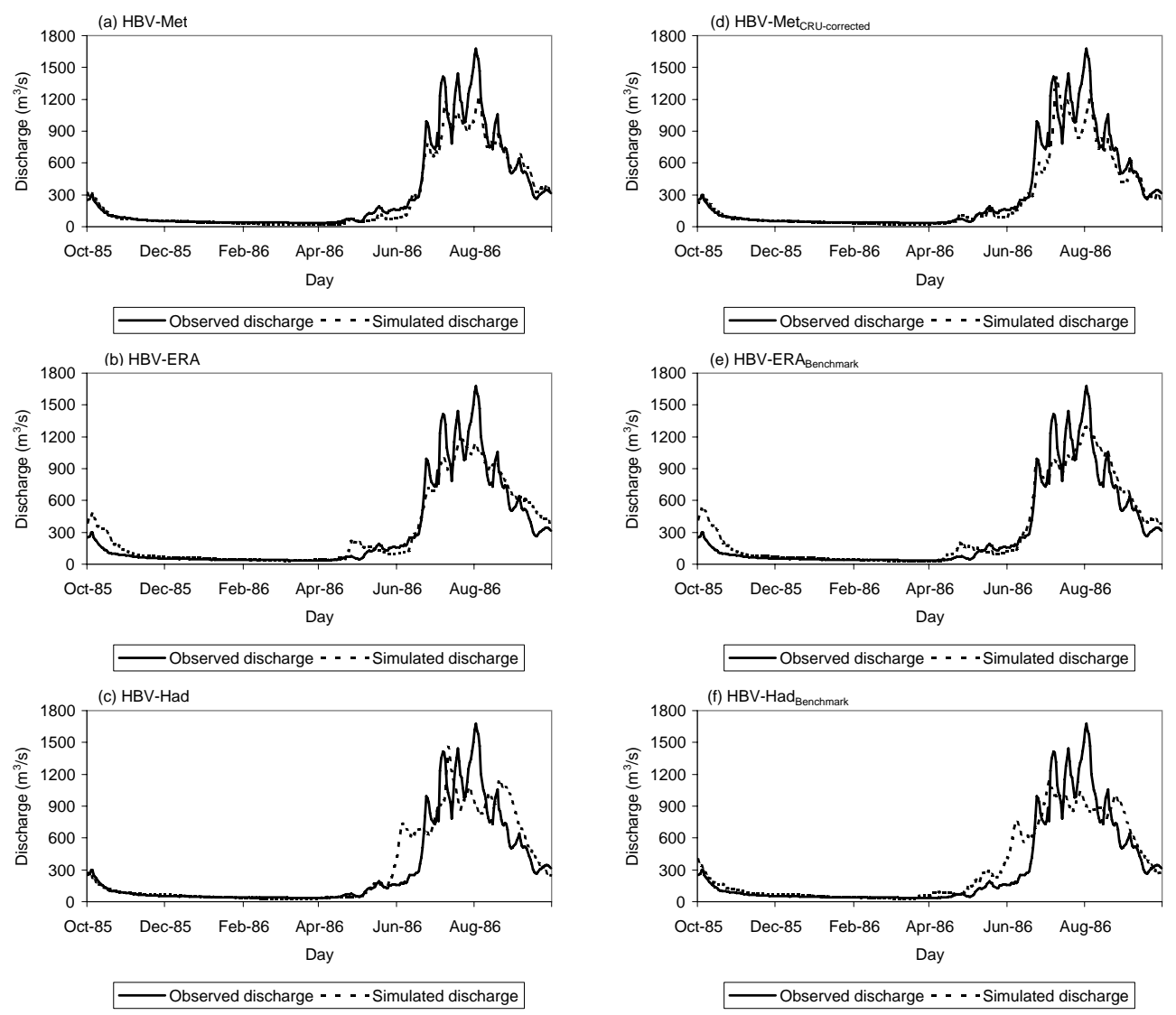

Fig. 8. Observed and simulated discharge $\left(\mathrm{m}^{3} / \mathrm{s}\right)$ of (a) HBV-Met, (b) HBV-ERA, (c) HBV-Had, (d) HBV-Met $\mathrm{CRU-corrected,} \mathrm{(e)} \mathrm{HBV-}$

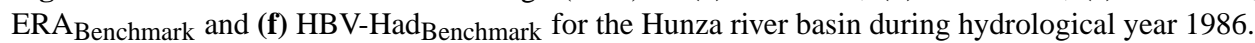

Table 6. Efficiency $Y$ of six HBV models using data sources different from the calibration sources in different river basins. The values of absolute relative deviations $(A R D)$ are given in parentheses. The italic values indicate efficiency $Y$ during calibration.

\begin{tabular}{|c|c|c|c|c|c|c|c|}
\hline \multirow[t]{2}{*}{ River Basin } & \multirow[t]{2}{*}{ Model } & \multicolumn{6}{|c|}{ Data Source Applied } \\
\hline & & Met Observations & PRECIS ERA & PRECIS Had & Met Observations CRU corrected & ERA-40 Reanalyses & HadAM3P GCM \\
\hline \multirow[t]{6}{*}{ Hunza } & HBV-Met & 0.87 & $0.65(25)$ & $0.53(39)$ & $-0.04(105)$ & $-0.25(128)$ & $0.41(53)$ \\
\hline & HBV-ERA & $0.49(45)$ & 0.89 & $0.73(18)$ & $0.13(86)$ & $-0.17(119)$ & $0.59(34)$ \\
\hline & HBV-Had & $0.56(27)$ & $0.86(12)$ & 0.77 & $0.06(92)$ & $-0.22(129)$ & $0.63(18)$ \\
\hline & HBV-Met $\mathrm{CRU}$-corrected & $-1.61(292)$ & $-1.16(239)$ & $-1.19(242)$ & 0.84 & $0.20(76)$ & $-0.95(213)$ \\
\hline & HBV-ERA Benchmark $_{1}$ & $-2.38(359)$ & $-1.94(312)$ & $-1.95(313)$ & $-0.09(110)$ & 0.92 & $-41.77(293)$ \\
\hline & HBV-Had Benchmark & $0.43(42)$ & $0.73(1)$ & $0.67(9)$ & $0.08(89)$ & $-0.21(129)$ & 0.74 \\
\hline \multirow[t]{6}{*}{ Gilgit } & HBV-Met & 0.82 & $0.55(33)$ & $0.62(24)$ & $-0.01(101)$ & $-0.12(114)$ & $0.40(52)$ \\
\hline & HBV-ERA & $0.57(24)$ & 0.75 & $0.63(16)$ & $-0.02(103)$ & $-0.16(121)$ & $0.57(24)$ \\
\hline & HBV-Had & $0.67(9)$ & $0.64(14)$ & 0.74 & $-0.02(103)$ & $-0.13(118)$ & $0.57(23)$ \\
\hline & HBV-Met ${ }_{\text {CRU-corrected }}$ & $-1.22(271)$ & $-1.44(301)$ & $-1.31(283)$ & 0.71 & $0.46(35)$ & $-1.47(305)$ \\
\hline & HBV-ERA Benchmark & $-1.35(265)$ & $-1.58(293)$ & $-1.45(278)$ & $0.29(64)$ & 0.82 & $-1.65(302)$ \\
\hline & HBV-Had Benchmark & $0.66(9)$ & $0.71(17)$ & $0.60(1)$ & $-0.09(115)$ & $-0.20(133)$ & 0.61 \\
\hline \multirow[t]{6}{*}{ Astore } & HBV-Met & 0.67 & $0.20(70)$ & $0.55(18)$ & $-0.02(103)$ & $0.12(83)$ & $0.47(30)$ \\
\hline & HBV-ERA & $0.31(46)$ & 0.58 & $0.37(36)$ & $-0.13(123)$ & $-0.09(115)$ & $0.40(30)$ \\
\hline & HBV-Had & $0.57(6)$ & $0.35(43)$ & 0.61 & $-0.08(113)$ & $0.02(97)$ & $0.57(6)$ \\
\hline & HBV-Met $\mathrm{CRU- \text {corrected }}$ & $-0.67(212)$ & $-1.39(333)$ & $-0.89(249)$ & 0.60 & $0.51(15)$ & $-0.98(264)$ \\
\hline & HBV-ERA Benchmark $_{\text {. }}$ & $-0.07(111)$ & $-0.66(200)$ & $-0.23(134)$ & $0.44(33)$ & 0.66 & $-0.31(147)$ \\
\hline & HBV-Had Benchmark & $0.51(15)$ & $0.39(35)$ & $0.55(7)$ & $-0.09(114)$ & $-0.01(102)$ & 0.59 \\
\hline
\end{tabular}

The efficiency is highest for the Hunza river basin compared to the Gilgit and Astore river basins as already observed during calibration. However, comparison of $Y$ values between different river basins has to be regarded carefully, because this statistical measure is strongly influenced by runoff variability. This may explain the relatively low values for the 

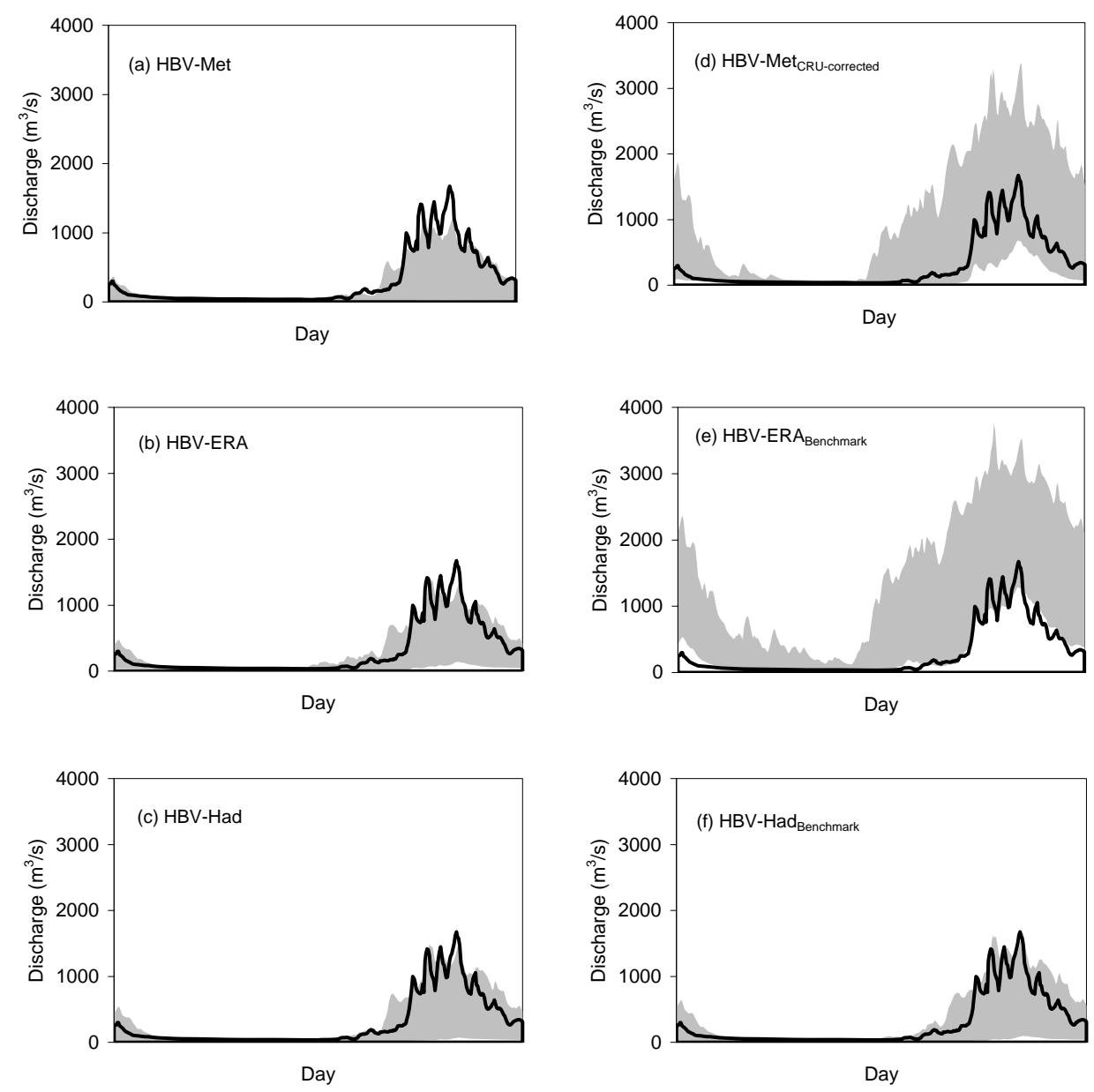

Fig. 9. Observed discharge (black line) and uncertainties (gray shade) in simulated discharge $\left(\mathrm{m}^{3} / \mathrm{s}\right)$ of (a) HBV-Met, (b) HBV-ERA, (c)

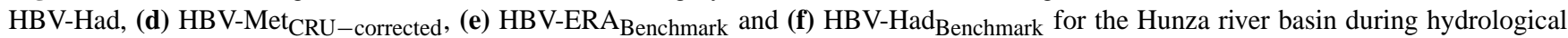
year 1986.

Astore river basin, where runoff variability is highest due to the small size of the river basin.

\subsection{Robustness of HBV models}

The robustness of HBV models is tested by calibrating the model with one data source and applying the data from the other five data sources. The Absolute Relative Deviation $(A R D)$ in the efficiency $(Y)$ is quantified by equation (4)

$A R D=100\left|\frac{Y_{a}-Y_{c}}{Y_{c}}\right|$

where $Y_{c}$ is the efficiency of the model during calibration and $Y_{a}$ is the efficiency of the model during the application of a different data source.

The efficiency $(Y)$ and Absolute Relative Error $(A R D)$ of the six HBV models using input data series from sources different from the data used in the model calibration are shown in Table 6. The values of the efficiencies show that overall performance of $\mathrm{HBV}-\mathrm{Had}$ (e.g. $-0.22<Y<0.86$ ) is somewhat higher compared to the other five models (e.g. $-2.38<Y<0.73)$. The $A R D$ values indicate that the errors in HBV-Met (e.g. $18 \%<A R D<128 \%$ ) are somewhat less compared to the errors in the other five models (e.g. $1 \%<A R D<359 \%$ ). The overall efficiency of HBV models driven by PRECIS RCM simulations is somewhat better (e.g. $-0.08<Y<0.86)$ compared to HBV models driven by driving forcing data (e.g. $-2.38<Y<0.73$ ). The errors in HBVHad and HBV-ERA (e.g. $9 \%<A R D<129 \%$ ) are somewhat less compared to the errors in $\mathrm{HBV}-\mathrm{Had}_{\mathrm{Benchmark}}$ and $\mathrm{HBV}$ -

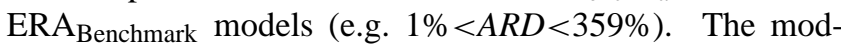
els HBV-Met ${ }_{C R U-\text { corrected and HBV-ERA }}$ Benchmark are the least efficient (e.g. $-2.38<Y<0.51$ ) compared to the other four models (e.g. $-0.25<Y<0.86$ ) and have higher ARD values (e.g. $15 \%<A R D<359 \%$ ) compared to the other four models (e.g. $1 \%<A R D<134 \%$ ). This may be due to the fact that in ERA-40 reanalysis data assimilation system precipitation is not relaxed towards observations. Therefore, ERA-40 precipitation might not be close to observations, particularly in a region with complex orography and lack- 
ing a dense observation station network as the HKH region of Pakistan (Wilfran Moufouma-Okia, Personal communication). Hence, the bias correction of ERA-40 data with respect to CRU data might have affected the inputs for the HBV model and consequently resulting in a poor perfor-

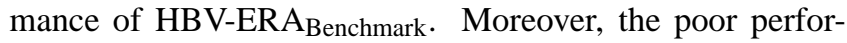
mance of HBV-Met ${ }_{\mathrm{CRU}}$-corrected may be due to the fact that for each river basin only one meteorological station is used as input of temperature and precipitation which introduces too much extreme behavior resulting in a poor performance

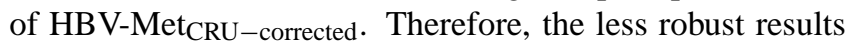
of HBV-Met ${ }_{\mathrm{CRU}}$-corrected and HBV-ERA Benchmark $_{\text {compared }}$ with other HBV models may be due to poor inputs to these models. The bias correction approach used only corrects the monthly mean and does not consider corrections in the variability. More sophisticated approaches in bias correction (e.g. Leander and Buishand, 2007) may give different results. The good performance of HBV-Met in terms of $A R D$ values may be related to the small precipitation biases (see Fig. 6). All these results indicate that the robustness of HBV models is affected by the input forcing data.

The effect of six different input forcing data series on the simulated discharge of $\mathrm{HBV}$ is also analyzed by calculating the uncertainty range. The uncertainty range in a HBV model is the difference between the maximum and minimum values of the six simulated discharge series. Figure 9 shows the uncertainty range in the six HBV models by applying inputs from six different data sources for the Hunza river basin during the 1986 hydrological year. The figures for the other two river basins are not given for redundancy. The uncertainties in the six HBV models show that six forcing data series have a large influence on the simulated discharge. The uncertainty range varies among the three river basins. The uncertainties are somewhat higher in HBV-Met ${ }_{\mathrm{CRU}}$-corrected and HBV-ERA $A_{\text {Benchmark }}$ compared to the uncertainties in HBVMet, HBV-ERA, HBV-Had and HBV-Had Benchmark. It is also observed that the uncertainties are less in the Hunza river basin compared to the Gilgit and Astore river basins. This may be due to the fact that the Hunza river basin is heavily glaciated $(34 \%)$ and temperature play a major role in the summer discharge, whereas the discharge of the less glaciated Gilgit (7\%) and Astore (16\%) river basins depends on the preceding winter precipitation (Archer, 2003). Since in the six different forcing data sets the temperature series are stable compared to the precipitation series and the bias correction technique applied has a larger impact on the precipitation series compared to the temperature series, this resulted in less uncertainties in the simulated discharge of the Hunza river basin compared to Gilgit and Astore river basins.

\section{Conclusions and recommendations}

Analysis of present day simulations shows that PRECIS possesses strong capacity to simulate spatial patterns of present climate characteristics. However, some quantitative biases also exist in the spatial patterns especially in mountain regions, where PRECIS RCM simulations underestimate temperature and overestimate precipitation with respect to CRU observations. The CRU temperature is also underestimated with respect to meteorological stations observations. The biases are highly influenced by the driving forcing data. The results of our PRECIS RCM simulations follow the same pattern as observed in other studies in the region using PRECIS (Kumar et al., 2006; Yinlong et al., 2006). In all three river basins the annual seasonal temperature cycle is present in all PRECIS simulations. The annual seasonal cycle of precipitation exhibits a stronger variability than the annual cycle of temperature. Overall, in the three river basins the magnitude of temperature biases is somewhat higher in PRECIS Had compared to PRECIS ERA simulation, whereas the magnitude of precipitation biases is somewhat less in PRECIS Had compared to PRECIS ERA simulation.

The parameters for six HBV models are estimated through univariate and multivariate sensitivity analysis. Univariate sensitivity analysis identified that there is a strong interdependence among gmelt, FC, DTTM and TT. Therefore, a multivariate sensitivity analysis is performed to optimize these interdependent and sensitive parameters. The parameter values of $\mathrm{HBV}-\mathrm{Met}_{\mathrm{CRU}}$-corrected and HBV-ERA $A_{\text {Benchmark }}$ are overestimated with respect to values given in the literature whereas the parameters estimated for all other models falls within the limits described in the literature. The calibration and validation results of the HBV model driven by six different data sources show that the HBV models can reproduce the discharge reasonably well. This shows that under present climate conditions the glacial component is well handled by the HBV model and the daily meteorological fluctuations are not very important for the hydrology of the region. This is also confirmed by the good performance of the HBV models with direct (HBV-Had ${ }_{\text {Benchmark }}$ ) and downscaled (HBV-Had) GCM inputs. Namely, daily variations in precipitation and temperature in these (downscaled) GCM results do not have a direct relation with the actual observed daily variations. Since HBV model performance at a daily time scale is satisfactory using these inputs, processes operating at longer time scales (e.g. glacier melt and snow melt) play a dominant role in this region and are well captured by HBV. Generally, during calibration and validation periods the overall performance of HBV-Met is somewhat better than the other models. Using the input data series from sources different from the data used in the model calibration shows that HBV-Had has the highest efficiency. However, HBV-Met is the most robust model as it has the smallest absolute relative errors. It is also observed that, the HBV models driven by PRECIS RCM simulations are more robust than HBV models driven by driving forcing data. Therefore, dynamically downscaled data improve hydrological modeling in data sparse regions and are preferred over GCM and reanalysis data. The uncertainties are higher in least efficient 
models (i.e. HBV-Met ${ }_{\mathrm{CRU}}$-corrected and HBV-ERA $\mathrm{B}_{\mathrm{Benchmark}}$ ) where the model parameters are also unrealistic. Moreover, the magnitude of uncertainties is higher in the river basins where discharge is dependent on the preceding winter precipitation (i.e. Gilgit and Astore river basins) compared to the river basin when the discharge is driven by energy inputs (i.e. Hunza river basin). In terms of both robustness and uncertainty ranges the HBV models calibrated with PRECIS output performed better than other calibrated models except for HBV-Met which has shown higher robustness. Therefore, it is recommended that in data sparse regions as the HKH region data from regional climate models are used as input in hydrological models for climate scenarios studies.

Acknowledgements. Part of this study was completed at ICTP, Trieste, Italy, which provided funding for two months fellowship for this work. The Higher Education Commission of Pakistan has also provided financial funding. The authors would like to thank the PRECIS team at Hadley Centre, Met Office, UK, for their comments and suggestions during the PRECIS simulations. The boundary data of different GCMs have been kindly supplied by David Hein on behalf of Hadley Centre, Met Office, UK The daily river discharge data have been taken from WAPDA, Pakistan. The authors also thank the HBV support team at SMHI for their useful comments and suggestions during the study.

Edited by: A. Bardossy

\section{References}

Akhtar, M.: The climate change impact on water resources of Upper Indus Basin-Pakistan, PhD thesis, University of the Punjab, Pakistan, 132 pp., 2008.

Akhtar, M., Ahmad, N., and Booij, M. J.: The impact of climate change on the water resources of Hindukush-KarakorumHimalaya region under different glacier coverage scenarios, J. Hydrol., 355, 148-163, 2008.

Archer, D. R..: Contrasting hydrological regime in Indus Basin, J. Hydrol., 274, 198-210, 2003.

Arnell, N. W.: Relative effects of multi-decadal climatic variability and changes in the mean and variability of climate due to global warming: future streamflow in Britain, J. Hydrol., 270, 195-213, 2003.

Bell, V. A., Kay, A. L., Jones, R. G., and Moore, R. J.: Development of a high resolution grid based river flow model for use with regional climate model out put, Hydrol. Earth Syst. Sci., 11, 532549, 2007, http://www.hydrol-earth-syst-sci.net/11/532/2007/.

Bergström, S.: The HBV model, Chapter 13 of Computer models of watershed hydrology, Water Resour. Publications, 443-476, 1995.

Bergström, S., Carlsson, B., Gardelin, M., Lindström, G., Pettersson, A., and Rummukainen, M.: Climate change impacts on the runoff in Sweden-assessments by global climate models, dynamical downscaling and hydrological modelling, Clim. Res., 16, 101-112, 2001.

Bonan, G. B.: The Land Surface Climatology of the NCAR Land Surface Model Coupled to the NCAR Community Climate Model, J. Climate, 11, 1307-1326, 1998.
Booij, M. J.: Impact of climate change on river flooding assessed with different spatial model resolutions, J. Hydrol., 303, 176198, 2005.

De Wit, M. J. M., Van den Hurk, B., Warmerdam, P. M. M., Torfs, P. J. J. F., Roulin, E., and Van Deursen, W. P. A.: Impact of climate change on low-flows in the river Meuse, Climatic Change, 82, 351-372, 2007.

Durman, C. F., Gregory, J. M., Hassell, D. C., Jones, R. G., and Murphy, J. M.: A comparison of extreme European daily precipitation simulated by a global and a regional climate model for present and future climates, Q. J. Roy. Meteor. Soc., 127, 10051015, 2001.

Fowler, H. J. and Kilsby, C. G.: Using regional climate model data to simulate historical and future river flows in northwest England, Climatic Change, 80, 337-367, 2007.

Fowler, H. J., Kilsby, C. G., and Stunell, J.: Modelling the impacts of projected future climate change on water resources in northwest England, Hydrol. Earth Syst. Sci., 11, 1115-1126, 2007, http://www.hydrol-earth-syst-sci.net/11/1115/2007/.

Giorgi, F. and Francisco, R.: Evaluating Uncertainties in the Prediction of Regional Climate Change, Geophys. Res. Lett., 27, 9, 1295-1298, 2000.

Giorgi, F. and Marinucci, M. R.: An investigation of the sensitivity of simulated precipitation to model resolution and its implications of climate studies, Mon. Weather Rev., 124, 148-166, 1996.

Giorgi, F., Brodeur, C. S., and Bates, G. T.: Regional climate change scenarios over the United States produced with a nested regional climate model, J. Climate, 7, 375-399, 1994.

Giorgi, F., Bi, X., and Pal, J. S.: Mean, interannual variability and trends in a regional climate change experiment over Europe. I. Present-day climate (1961-1990), Clim. Dynam., 22, 733-756, 2004.

Gordon, C. C., Cooper, C., Senior, C. A., Banks, H., Gregory, J. M., Mitchell, J. F. B., and Wood, R. A.: The simulation of SST, sea ice extents and ocean heat transport in a version of the Hadley centre coupled model without flux adjustment, Clim. Dynam., 16, 147-168, 2000.

Graham, L. P., Andreasson, J., and Carlsson, B.: Assessing climate change impacts on hydrology from an ensemble of regional climate models, model scales and linking methods - a case study on the Lule River basin, Clim. Change, 81, 293-307, 2007.

Guo, S.,Wang, J., Xiong, L., Yin, A., and Li, D.: A macro-scale and semi-distributed monthly water balance model to predict climate change impacts in China, J. Hydrol., 268, 1-15, 2002.

Gutowski, W. J., Decker, S. G., Donavon, R. A., Pan, Z., Arritt, R. W., and Takle, E. S.: Temporal-spatial scales of observed and simulated precipitation in central U.S. climate, J. Climate, 16, 3841-3847, 2003.

Hay, L. E., and Clark, M. P.: Use of statistically and dynamically downscaled atmospheric model output for hydrologic simulations in three mountainous basins in the western United States, J. Hydrol., 282, 56-75, 2003.

Hay, L. E., Clark, M. P., Wilby, R. L., Gutowski, W. J., Leavesley, G. H., Pan, Z., Arritt, R. W., and Takle, E. S.: Use of regional climate model output for hydrological simulations, J. Hydrometeorol., 3, 571-590, 2002.

Hudson, D. A. and Jones, R. G.: Regional climate model simulations of present-day and future climates over southern Africa, 
Technical Note 39, Hadley Centre for Climate Prediction and Research, Met Office, Bracknell, UK, 2002.

Jones, R. G., Noguer, M., Hassell, D. C., Hudson, D., Wilson, S. S., Jenkins, G. J., and Mitchell, J. F. B.: Generating high resolution climate change scenarios using PRECIS, Met Office Hadley Centre, Exeter, UK, 40 pp., 2004.

Kay, A. L., Jones, R. G., and Reynard, N. S.: RCM rainfall for UK flood frequency estimation, I. Method and validation, J. Hydrol., 318, 151-162, 2006.

Krysanova, V., Bronstert, A., and Muller-Wohlfeil, D. I.: Modelling river discharge for large drainage basins: from lumped to distributed approach, Hydrol. Sci. J., 44, 313-331, 1999.

Kumar, R. K., Sahai, A. K., Kumar, K. K., Patwardhan, S. K., Mishra, P. K., Revadekar, J. V., Kamala, K., and Pant, G. B.: High-resolution climate change scenarios for India for the $21 \mathrm{st}$ century, Current Science 90, 334-345, 2006.

Leander, R. and Buishand, T. A.: Resampling of regional climate model output for the simulation of extreme river flows. J. Hydrol., 332, 487-496, 2007.

Liden, R. and Harlin, J.: Analysis of conceptual rainfall-runoff modelling performance in different climates, J. Hydrol., 238, 231-247, 2000.

Lindström, G., Johansson, B., Persson, M., Gardelin, M., and Bergström, S.: Development and test of the distributed HBV-96 model, J. Hydrol., 201, 272-288, 1997.

McGregor, J. L.: Regional climate modeling, Meteorol. Atmos. Phys., 63, 105-117, 1997.

Menzel, L., and Bürger, G.: Climate change scenarios and runoff response in the Mulde catchment (Southern Elbe, Germany), J. Hydrol., 267, 53-64, 2002.

Menzel, L., Thieken, A. H., Schwandt, D., and Bürger, G.: Impact of climate change on the regional Hydrology-Scenarios-Based modelling studies in the German Rhine Catchment, Natural Hazards, 38, 45-61, 2006.

Mitchell T. D. and Jones., P. D.: An improved method of constructing a database of monthly climate observations and associated high-resolution grids. International Journal of Climatology, 25, 693-712, 2005.

Murphy, J. M., Sexton, D., Barnett, D., Jones, G., Webb, M., Collins, M., and Stainforth, D.: Quantification of modelling uncertainties in a large ensemble of climate change simulations, Nature, 430, 768-772, 2004.

Nash, J. E. and Sutcliffe, J. V.: River flow forecasting through conceptual models 1: a discussion of principles, J. Hydrol., 10, 282290, 1970.

New, M. G., Hulme, M., and Jones, P. D.: Representing twentieth century space time climate variability. Part I. Development of a 1961-1990 mean monthly terrestrial climatology, J. Climate, 12, 829-856, 1999.

New, M. G., Hulme, M., and Jones, P. D.: Representing twentieth century space time climate fields. Part II. Development of a 1901-1996 mean monthly terrestrial climatology, J. Climate, 13, 2217-2238, 2000.

Pilling, C. G. and Jones, J. A. A.: The impact of future climate change on seasonal discharge, hydrological processes and extreme flows in the Upper Wye experimental catchment, midWales, Hydrol. Proc., 16, 1201-1213, 2002.

Rango, A.: Worldwide testing of the snowmelt runoff model with applications for predicting the effects of climate change, Nordic
Hydrol., 23, 155-172, 1992.

SIHP.: Snow and Ice Hydrology Project, Upper Indus Basin, Overall. Report, WAPDA-IDRC-Wilfrid Laurier University, 179 pp., 1990.

SMHI: Integrated hydrological modelling system (IHMS), Manual version 5.6, SMHI, Norrkoping, Sweden, 2005.

Solman, S. A., Nunez, M. N., and Cabre, M. F.: Regional climate change experiments over southern South America. I: present climate, Clim. Dynam., 30, 533-552, 2008.

Te Linde, A. H., Aerts, J. C. J. H., Hurkmans, R. T. W. L., and Eberle, M.: Comparing model performance of two rainfallrunoff models in the Rhine basin using different atmospheric forcing data sets, Hydrol. Earth Syst. Sci., 12, 943-957, 2008, http://www.hydrol-earth-syst-sci.net/12/943/2008/.

Uhlenbrook, S., Seibert, J., Leibundgut, C., and Rodhe, A.: Prediction uncertainty of conceptual rainfall-runoff models caused by problems in identifying model parameters and structure, Hydrol. Sci. J., 44, 779-797, 1999.

Uppala, S. M., Kållberg, P. W., Simmons, A. J., Andrae, U., Da Costa Bechtold, V., Fiorino, M., Gibson, J. K., Haseler, J., Hernandez, A., Kelly, G. A., Li, X., Onogi, K., Saarinen, S., Sokka, N., Allan, R. P., Andersson, E., Arpe, K., Balmaseda, M. A., Beljaars, A. C. M., Van De Berg, L., Bidlot, J., Bormann, N., Caires, S., Chevallier, F., Dethof, A., Dragosavac, M., Fisher, M., Fuentes, M., Hagemann, S., Holm, E., Hoskins, B. J., Isaksen, L., Janssen, P. A. E. M., Jenne, R., McNally, A. P., Mahfouf, J. F., Morcrette, J. J., Rayner, N. A., Saunders, R. W., Simon, P., Sterl, A., Trenberth, K. E., Untch, A., Vasiljevic, D., Viterbo, P., and Woollen, J.: The ERA-40 re-analysis, Q. J. Roy. Meteor. Soc., 131, 2961-3012, 2005.

Wang, S., McGrath, R., Semmler, T., Sweeney, C., and Nolan, P.: The impact of the climate change on discharge of Suir river catchment (Ireland) under different climate scenarios, Nat. Hazards Earth Syst. Sci., 6, 387-395, 2006, http://www.nat-hazardsearth-syst-sci.net/6/387/2006/.

Watson, R. T., Zinyowera, M. C., and Moss, R. H.: Climate Change 1995: Impacts, Adaptations, and Mitigations of climate change, Cambridge University Press, 889 pp., 1996.

Wilby, R. L., Hay, L. E., and Leavesley, G. H.: A comparison of downscaled and raw GCM output: Implications for climate change scenarios in the San Juan River Basin, Colorado. J. Hydrol., 225, 67-91, 1999.

Wilson, M. F. and Hendersen-Sellers, A.: A global archive of land cover and soils data for use in general circulation models. J. Climatol., 5, 119-143, 1985.

Wilson, S., Hassell, D., Hein, D., Jones, R., and Taylor, R.: Installing and using the Hadley Centre regional climate modelling system, PRECIS (version 1.4), Met Office Hadley Centre, Exeter, UK, 2005.

Winger, M., Gumpert, M., and Yamout, H.: KarakorumHindukush-western Himalaya: assessing high-altitude water resources, Hydrol. Processes, 19, 2329-2338, 2005.

Yinlong, X., Yong, Z., Erda, L., Wantao, L., Wenjie, D., Jones, R., Hassell, D., and Wilson, S.: Analysis on the climate change responses over China under SRES B2 scenario using PRECIS, Chinese Science Bulletin, 51, 2260-2267, 2006. 